\title{
Evaluation of Onset and Cessation of Rainfall and Temperature on Maize Yield in Akure, Ondo State, Nigeria
}

\author{
Idumu A. Mosunmola1, Ishaya K. Samaila², Bello Emmanuel'1, Ifeka Adolphus ${ }^{3}$ \\ ${ }^{1}$ Nigerian Meteorological Agency, Abuja, Nigeria \\ ${ }^{2}$ Nasarawa State University, Keffi, Nigeria \\ ${ }^{3}$ Federal University of Technology Akure, Nigeria \\ Email: mosskayy@yahoo.co.uk
}

How to cite this paper: Mosunmola, I.A., Samaila, I.K., Emmanuel, B. and Adolphus, I. (2020) Evaluation of Onset and Cessation of Rainfall and Temperature on Maize Yield in Akure, Ondo State, Nigeria. Atmospheric and Climate Sciences, 10, 125-145. https://doi.org/10.4236/acs.2020.102006

Received: October 28, 2019

Accepted: March 17, 2020

Published: March 20, 2020

Copyright $\odot 2020$ by author(s) and Scientific Research Publishing Inc. This work is licensed under the Creative Commons Attribution International License (CC BY 4.0).

http://creativecommons.org/licenses/by/4.0/

\begin{abstract}
Temperature and rainfall are important variables that affect maize yield, and as such this study aimed at evaluating the impact of onset, cessation of rainfall and temperature on maize yield in Akure. To achieve this objective, climatic parameters comprising daily rainfall and temperature (maximum and minimum temperature) 1981-2016 for Akure, were obtained from the archives of the Nigerian Meteorological Agency, NiMet. Annual maize yield data for the same period 2000-2016 were obtained from Ondo State Agricultural Development Programme. Walter's method, as modified by [1], was then used to determine the onset, cessation and length of growing season. The significance of the annual trend of these climatic parameters was also tested using an approach involving z-test and p-value analysis. Likewise, the significance of all the climatic parameters contributing to maize yield was also determined based on the p-value approach under a null hypothesis. The coefficients of determination $\left(R^{2}\right)$ and Pearson correlation coefficient $(r)$ in relation to the SLR and MLR models were calculated. The result showed a slight decreasing trend of rainfall, increasing trend of maximum, minimum and maize yield. Their associated p-values are $0.6925,0.5794,0.5136$ and 0.0630 , which showed that the trend over the years was not statistically significant at the $1 \%$, $5 \%$ and $10 \%$ levels; however maize yield was significant at $10 \%$ significant level. The mean onset, cessation and length of growing season for Akure were $8^{\text {th }}$ March $\pm 9,21^{\text {st }}$ October \pm 21 and 239 days \pm 27 days. The relationship between maize yield and all climatic variables in association with SLR model showed that rainfall was the major contributing variable to maize yield in Akure, Ondo State at all significant levels (p-value $(0.009539)<0.01,0.05$ and $\left.1 r=61 \%, R^{2}=37 \%\right)$. The p-value in association with MLR model, also
\end{abstract}


showed that rainfall was significant at $5 \%$ and $10 \%$. P $(0.019412)<0.1$ and $0.05, r=72 \%, R^{2}=51 \%$.

\section{Keywords}

Onset, Cessation, Rainfall, Temperature, Maize Yield

\section{Introduction}

The knowledge and variation of rainfall onset, cessation and length of the growing season both at national and international level is paramount, as many agricultural activities and planning for sustainable food yield depend on rainfall for land preparation, seed/crop planting and harvesting [2].

[3] observed that the irregularity of onset and cessation of the rainy season across many regions over the years had made it difficult for farmers to optimize the seed planting period and adjust to the length of the growing season. The resultant effect is the decrease of agricultural yield and an increase in the risk of hunger.

In most tropical regions, rainfall onset and retreat dates are important parameters in the agricultural calendar [3]. Especially as many regions over the world are expected to experience substantial modifications as a result of climate variability. These changes are expected to affect the onset and cessation of the rainy season which has become irregular over the years [4]. Posing a problem for farmers as regards optimization of the seed planting and the need to adjust to the length of the growing season [5] [6]. Therefore, the determination of the onset and retreat dates of the rainy season in various regions across the world has become a challenge for many researchers [7].

In Nigeria, rain falls in different months of the year at different places, as the rain belt appears to follow the relative northward and southward movements of the sun [8]. In this situation of a marked seasonal rainfall regime, variability of the onset and cessation of rain is highly significant, and its estimation and prediction are necessary [9]. A delay of 1 or 2 weeks in the onset is sufficient to destroy the hopes of a normal harvest while a "false start" of planting, encouraged by a false start of rainfall may be followed by prolonged dry spells whose duration of two weeks or more may be critical to plant germination and growth [5].

This paper aims to evaluate the annual variations and patterns in the rainfall onset/cessation dates, length of growing season and temperature in relation to maize yield in Akure. The specific objectives of the study are to: determine the trends in rainfall and temperature, the trend in maize yield of the years covered by the study, the mean dates of the onset, cessation and length of the growing season for the period of 2000 to 2016 and examine the Correlation between the maize yield and rainfall characteristic and temperature in the study. 


\section{Methodology}

\subsection{Study Area}

Akure is a city in south-western Nigeria and is the largest city and capital of Ondo State. The people of Akure are of the Yoruba ethnic group. The city had a population of 556,300 as at the 2015 population census. Akure is the capital of Ondo State, Nigeria situated approximately between geographical coordinates of (Longitudes $5^{\circ} 8^{\prime}$ and $5^{\circ} 15^{\prime}$ East of Greenwish meridian) and (Latitudes $7^{\circ} 20^{\prime}$ and $7^{\circ} 10^{\prime}$ North of the equator). Capital of Ondo State. Main towns are, Alagbaka, Araromi, Ijapo Estate, Gbadare Ondo Bye pass, Ijomu, Oba, Owode, Oke AroDanjuma, and so on. It is bounded by Owo Local Government Area in the east, Akure North and Ifedore Local Government Areas in the north, Ile-Oluji/Oke-Igbo Local Government Area in the west and Idanre Local Government Area in the south (Figure 1).

The climate of Akure, Ondo State is equatorial rain forest belt, with distinct wet and dry seasons. The climate of Akure is influenced by rain bearing southwest monsoon winds from the Atlantic Ocean. High atmospheric temperature and high relative humidity characterizes the climate. The rainy season last for about seven months (April-October).

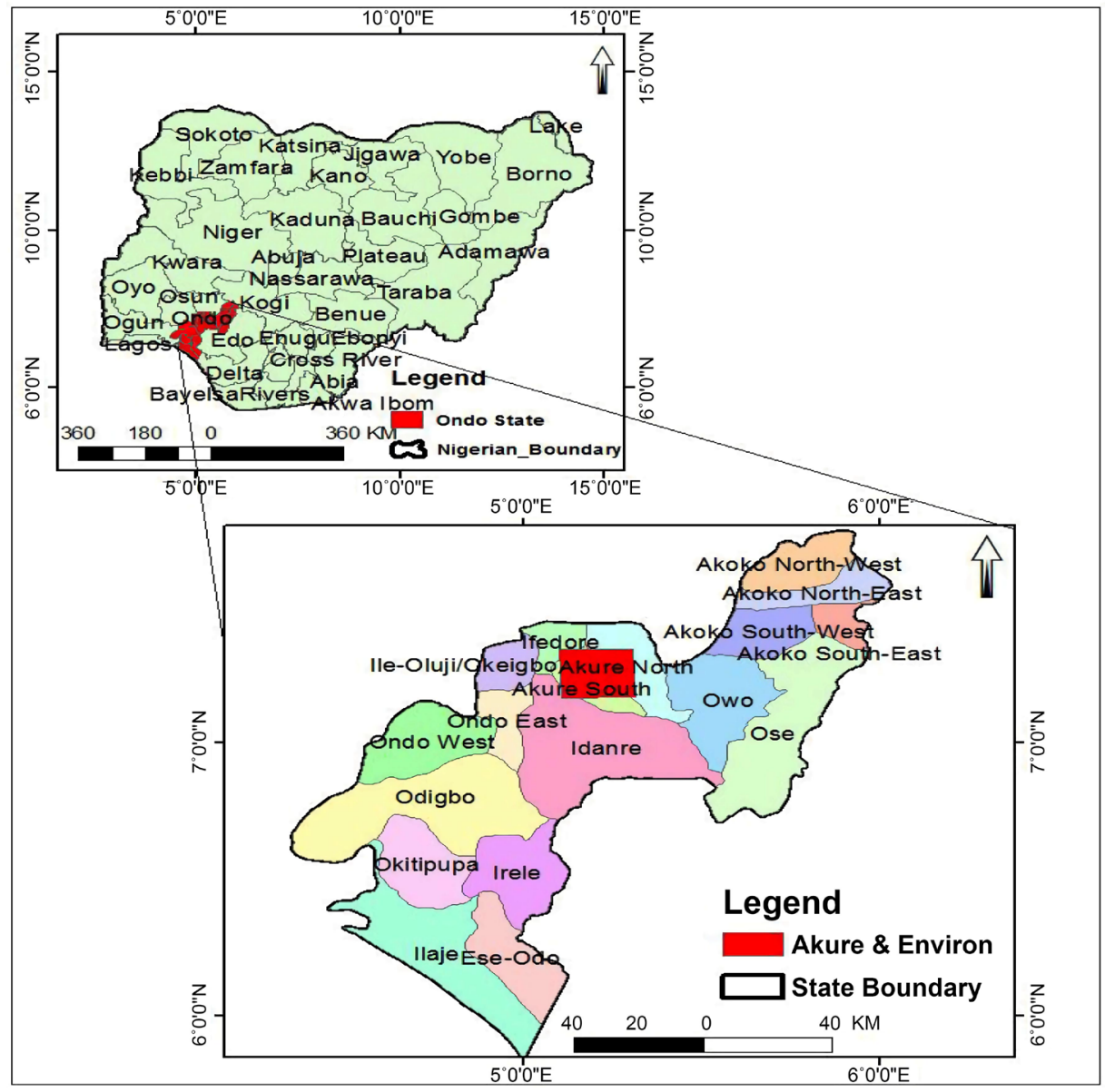

Figure 1. Map of Ondo State showing Akure. 


\subsection{Materials and Methods}

Daily rainfall values in $\mathrm{mm}$ and daily maximum and minimum temperature values in $\left({ }^{\circ} \mathrm{C}\right)$ was used for the study area over 1981 to 2016. Maize yield from 2000 to 2016 for the study area was also used. Daily rainfall and temperature data was obtained from the archives of Nigerian Meteorological Agency from 1981 to 2016. Maize yield for the study area (2000 to 2016) was collected from Agricultural Development Programme in Ondo State. The rainfall total (monthly and annual amounts) of the study area was computed from the daily rainfall data collected through cumulative analysis (summation). Other statistical methods including arithmetic mean, mean deviation, standard deviation, coefficient of variation and time series analysis were employed to establish the trend in the annual rainfall amount.

Monthly rainfall amount: This was computed for the study area from the daily rainfall amount using the equation

$$
M_{R}=\frac{1}{n} \sum_{i=1}^{n} R_{i}
$$

where: $M_{R}=$ monthly rainfall amount $(\mathrm{mm})$;

$R_{i}=$ daily rainfall amount at the study area;

$n=$ number of days in a month;

$i=$ the days of the months.

Annual rainfall amount: The annual rainfall total was calculated for the study area from the monthly rainfall amount. The equation used is:

$$
A_{R}=\frac{1}{12} \sum_{i=1}^{12} R_{i}
$$

where: $M_{R}=$ monthly rainfall amount $(\mathrm{mm})$;

$R_{i}=$ daily rainfall amount at the study area;

$n=$ number of days in a month;

$i=$ the days of the months.

The mean monthly rainfall amount: The mean annual rainfall amount for the period of 36 years was computed for the study area by the equation:

$$
\overline{R R_{j}}=\sum_{j=1}^{30} R_{j} / 36
$$

where: $\overline{R R_{j}}=$ the mean monthly rainfall amount for Akure over the 36-year period.

Arithmetic Mean: Arithmetic Mean or the mean of a set of n-numbers: $x_{1}, x_{2}, x_{3}, \cdots, x_{n}$ denoted by $\bar{x}$ is the sum of these variables divided by n. mathematically expressed as:

$$
\text { Mean, } \bar{x}=\frac{\sum x}{n}
$$

where $\bar{X}=$ Mean of daily rainfall amount;

$$
\begin{aligned}
& \sum x=\text { sum of daily rainfall for the month }\left(x_{1}+x_{2}+x_{3}+\cdots+x_{n}\right) \text {; } \\
& n=\text { number of days in a month. }
\end{aligned}
$$


Mean Deviation: Mean deviation was used to measure the extent variability in the data set. It is expressed mathematically as:

$$
\text { Mean deviation }=\frac{\sum(x-\bar{x})}{n}
$$

where $x=$ the rainfall amount in a day/month;

$\bar{X}=$ Mean of daily/monthly rainfall amount;

$n=$ number of days in a month/months in a year.

Standard Deviation: Standard Deviation is a measure of dispersion of a set of sample variables from the mean. This, being a basis for measure of variability, served to collate information on the annual variation of rainfall in the study area. The formula is given by:

$$
S=\sqrt{\frac{n \sum\left(x^{2}\right)-\left(\sum x\right)^{2}}{n(n-1)}}
$$

where $S=$ Standard deviation;

$x=$ rainfall amount in a day, in a month or year;

$n=$ number of days in a month or year for which rainfall was measured.

Coefficient of variation (C.V)

$$
C . V=\frac{S}{\bar{x}} \times 100
$$

where $C . V=$ Coefficient of variation;

$S=$ Standard deviation;

$\bar{X}=$ mean.

The test for significance begins with stating a null hypothesis $\left(\mathrm{H}_{0}\right)$ for the slope or trend associated to any of the climatic parameter and is usually constructed as follows:

$$
\mathrm{H}_{0}: S_{k}=0 \text {, }
$$

where $k=1$ or 2 or 3 or 4 or 5 or 6 .

$$
\mathrm{H}_{1}: S_{k} \neq 0 \text {. }
$$

Here all the $S_{k}$ (with $k=1,2,3,4,5,6$ ) represent the trend or slope obtained by fitting any of the climatic parameters to a trend line against time. The trend line was obtained using method of least squares; the $y$ axis here would be any of the climatic parameters while the $\mathrm{x}$ axis would be time in years, i.e. from 1981 to 2016.

The onset and cessation dates was determined using the Walters formulation as modified by (Olaniran, 1983). The method is expressed as:

$$
\text { Onset } / \text { End }=\frac{\mathrm{DM}}{\mathrm{TM}} *(51-\mathrm{AP})
$$

where, $\mathrm{DM}=$ number of days in the month containing the onset;

$\mathrm{TM}=$ total rainfall for the month in which accumulated rainfall exceeds 51 $\mathrm{mm}$;

$\mathrm{AP}=$ accumulated rainfall of previous months just before the month in refer- 
ence;

$51 \mathrm{~mm}=$ the threshold of rainfall for both Onset/End month.

where such onset date was followed by rainfall amount less than $51 \mathrm{~mm}$, the next rain day date that is up to $51 \mathrm{~mm}$ or more will be chosen. The null and the alternative hypothesis under $\mathrm{t}$-distribution is given by

$$
\mathrm{H}_{0}: \beta_{k}=0 \text {, }
$$

where $k=1$ or 2 or 3 or 4 or 5 .

$$
\mathrm{H}_{1}: \beta_{k} \neq 0 \text {. }
$$

And here, it would state that the coefficients associated to each of the climatic parameters, $\beta_{k}$ (with $k=1,2,3,4,5$ ), is zero or insignificant according to the arrangement given in eqn11. Having stated the hypothesis, a sample is drawn and the $t$-value associated with the parameter calculated. Thereafter the corresponding $\mathrm{p}$-value of the parameter determined. If the calculated $\mathrm{p}$-value of the parameter is less than the level of significance, the null hypothesis would be rejected and it was concluded that the climatic parameter's contribution to maize yield is significant at the indicated level of significance If however, the p-value is greater than the significant level, the null hypothesis cannot the rejected and it was concluded that the parameter's contribution to maize yield is not significant at the indicated level of significance.

The sample correlation coefficient, $r$ is an estimate of the population correlation, $\rho$ and is used to measure the strength of the linear relationship in the sample observations. Correlation ranges between -1 and 1 . The closer to -1 , the stronger the negative linear relationship; the closer to 1 , the stronger the positive linear relationship and the closer to 0 , the weaker the linear relationship.

$$
r=\frac{\sum(x-\bar{x})(y-\bar{y})}{\sqrt{\left[\sum(x-\bar{x})^{2}\right]\left[\sum(y-\bar{y})^{2}\right]}}
$$

where:

$$
\begin{aligned}
& r=\text { Sample correlation coefficient; } \\
& n=\text { Sample size; } \\
& x=\text { Value of the independent variable; } \\
& y=\text { Value of the independent variable. }
\end{aligned}
$$

\section{Results and Discussion}

Results of the study are discussed in the following categories: rainfall, maximum and minimum temperature trend, maize yield trend, onset, cessation and length of growing season, relationship between maize yield and rainfall, relationship between maize yield and onset, relationship between maize yield and cessation, relationship between maize yield and length of growing season, relationship between maize yield and minimum temperature, relationship between maize yield and maximum temperature, multiple linear regression model involving maize yield and the climatic parameters. 


\subsection{Rainfall Trend over Akure}

Figure 2 presents rainfall trends over Akure for the period under study. The temporal or yearly distribution as presented in Figure 2 ranged between lowest rainfall value of $1026.4 \mathrm{~mm}$ in 2001, and highest value of $1903.3 \mathrm{~mm}$ in 1991 . The implication of this is that year 1991 presented an opportunity for increased food yield, but also has the highest risk of flooding and environmental degradation. With an average rainfall of $1428.4 \mathrm{~mm}$ and a standard deviation of 108.6 $\mathrm{mm}$, this implies that in any given year annual rainfall over this location could be expected to increase or decrease by $108.7 \mathrm{~mm}$. A slight downward trend is observed through the years in the values of this parameter, but is however, rendered not statistically significant at all the chosen levels of significance $(0.01$, 0.05 , and 0.1 ) based on the calculated p-value (0.6925). The slight decreasing trend observed in this study agrees with [10] who observed that in the past three decades, rainfall in the West African region has been decreasing, more importantly, this trend is getting more complex.

\subsection{Maximum Temperature Trend over Akure}

Figure 3 presents maximum temperature trends over Akure for the period under study. It revealed a slight increase or upward trend indicating that the lowest maximum temperature of $30.4^{\circ} \mathrm{C}$ was recorded in 1986 while the highest maximum value of $31.9^{\circ} \mathrm{C}$ was observed in 2011 . The associated $\mathrm{p}$-value (0.122) indicates that the trend is not significant at all the chosen levels of significance i.e. $0.01,0.05$ and 0.1 levels based on the hypothesis in Equation (7). Mean temperature of $31.7^{\circ} \mathrm{C}$ with a standard deviation of 0.2 and a low inter-annual coefficient of variation of $0.78 \%$. Year 2000, 2010, 2011, and 2016 had maximum temperatures above the mean value, with temperature values of $31.8^{\circ} \mathrm{C}, 31.9^{\circ} \mathrm{C}$, $31.8^{\circ} \mathrm{C}$ and $31.9^{\circ} \mathrm{C}$ for year 2000,2010 and 2016 . Similarly, year 2004, 2008, and 2014 had temperature values of $30.8^{\circ} \mathrm{C}, 31.1^{\circ} \mathrm{C}$, and $31.2^{\circ} \mathrm{C}$ below the mean

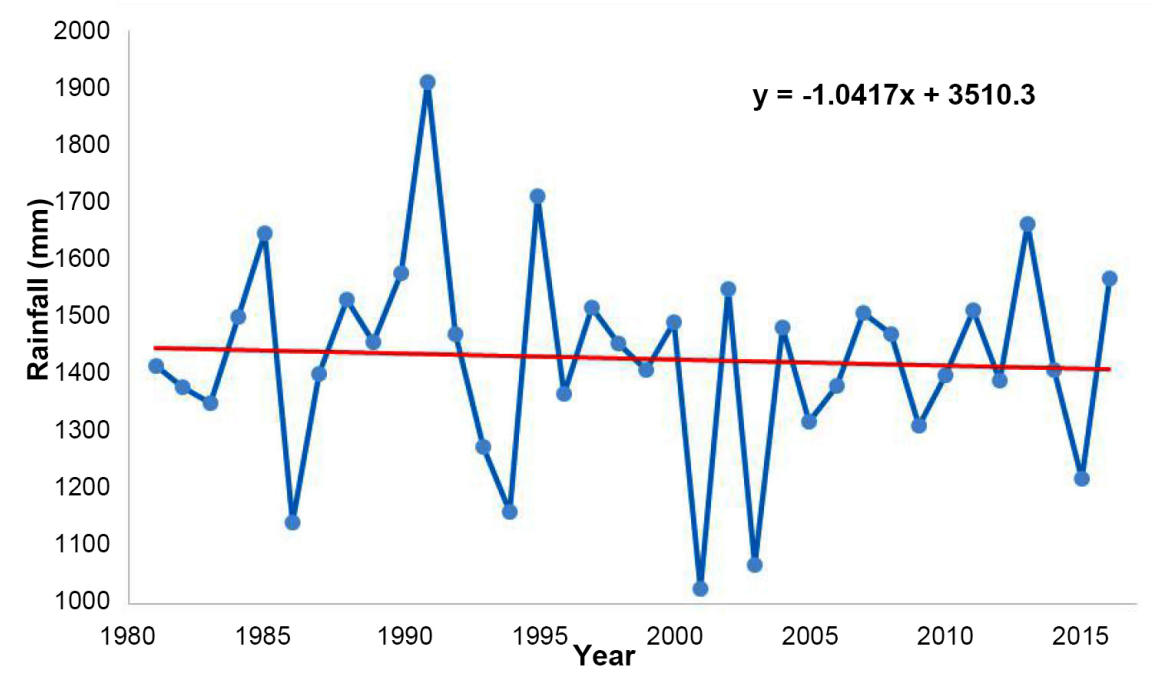

Figure 2. Yearly rainfall trend in Akure (1981-2016). 


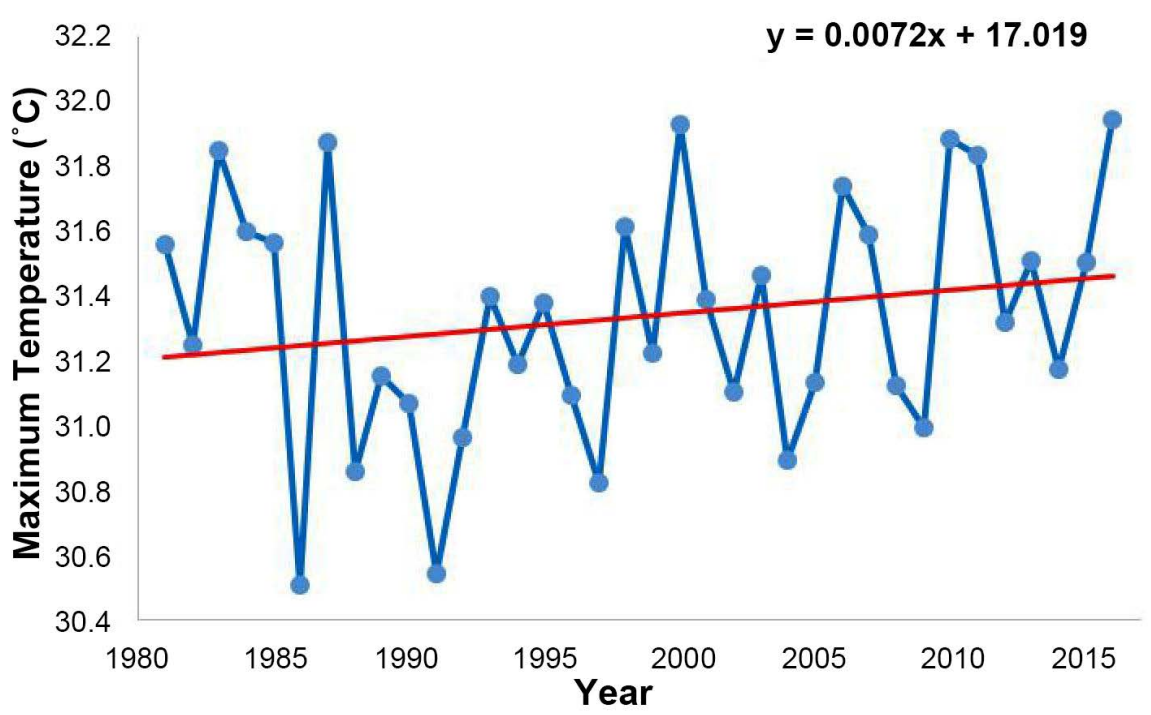

Figure 3. Yearly maximum temperature trend in Akure (1981-2016).

temperature for the period of study with varying maize yield values. The implication of this is that any variation in maize yield may not directly be the result of temperature variation. This is very good for Akure especially as [11] found that warming trends in temperature was deemed responsible for suppression of global agricultural productivity during the past 30 years.

\subsection{Minimum Temperature Trend over Akure}

Figure 4 presents minimum temperature trends over Akure for the period under study.

An upward trend or increase was observed as postulated by some group of people that temperatures across the continent have increased by $0.5^{\circ} \mathrm{C}$ or more, with minimum temperatures rising faster than maximum temperatures [12]. [13] also observed that minimum air temperatures affect nighttime plant respiration rates and can potentially reduce biomass accumulation and crop yield. However, the minimum temperature obtained in Akure may favour maize yield. A lowest minimum temperature of $20.13^{\circ} \mathrm{C}$ was observed in 1992 and highest minimum of $22.13^{\circ} \mathrm{C}$ was observed in 2016 . The associated p-value (0.5136) indicates that the trend is not significant at all the chosen levels of significance i.e. $0.01,0.05$ and 0.1 which implies that the slight increase observed is not statistically significant. Standard Deviation of 0.52 , Mean minimum $21.8^{\circ} \mathrm{C}$ and C.V $=$ $2.4 \%$. Years 2007,2010 and 2016 had temperature values of $21.9^{\circ} \mathrm{C}, 22.0^{\circ} \mathrm{C}$ and $22.2^{\circ} \mathrm{C}$ were all above the mean minimum temperature value, subsequently Year 2000, 2002, 2003, 2006, 2008 and 2013 were $21.1^{\circ} \mathrm{C}, 21.2^{\circ} \mathrm{C}, 21.7^{\circ} \mathrm{C}, 21.2^{\circ} \mathrm{C}$, $21.1^{\circ} \mathrm{C}$ respectively had minimum temperatures below the mean values.

\subsection{Maize Yield Trend over Akure}

Figure 5 presents minimum temperature trends over Akure for the period under study. It showed that maize yield over Akure has been on the increase during the 


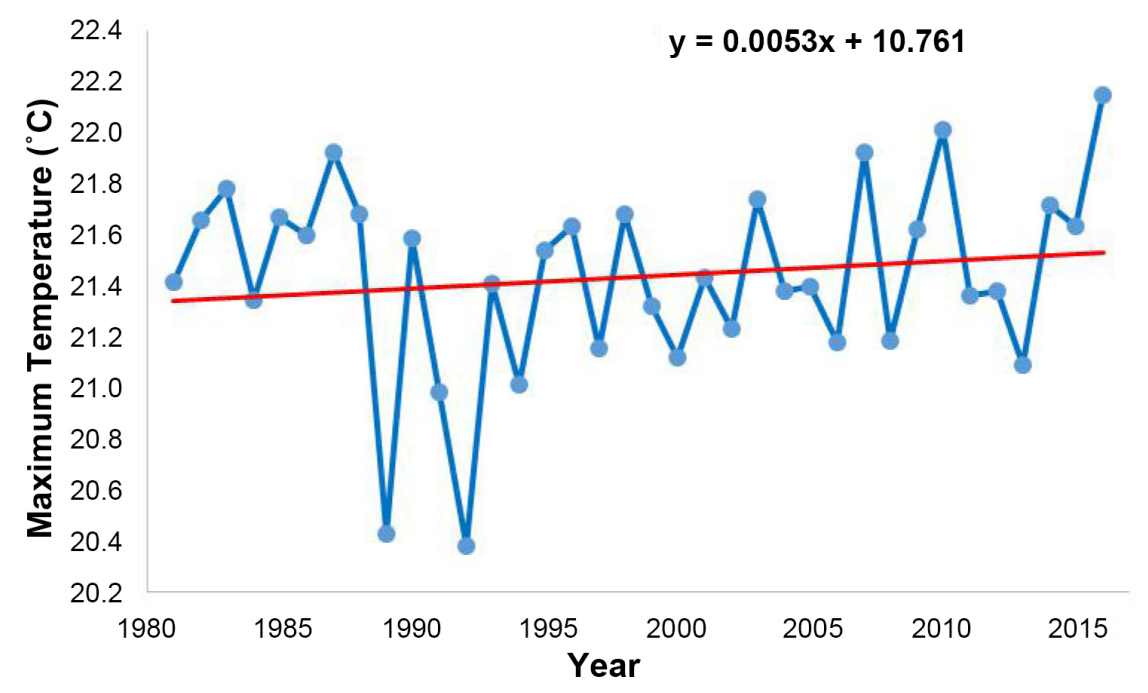

Figure 4. Yearly minimum temperature trend in Akure (1981-2016).

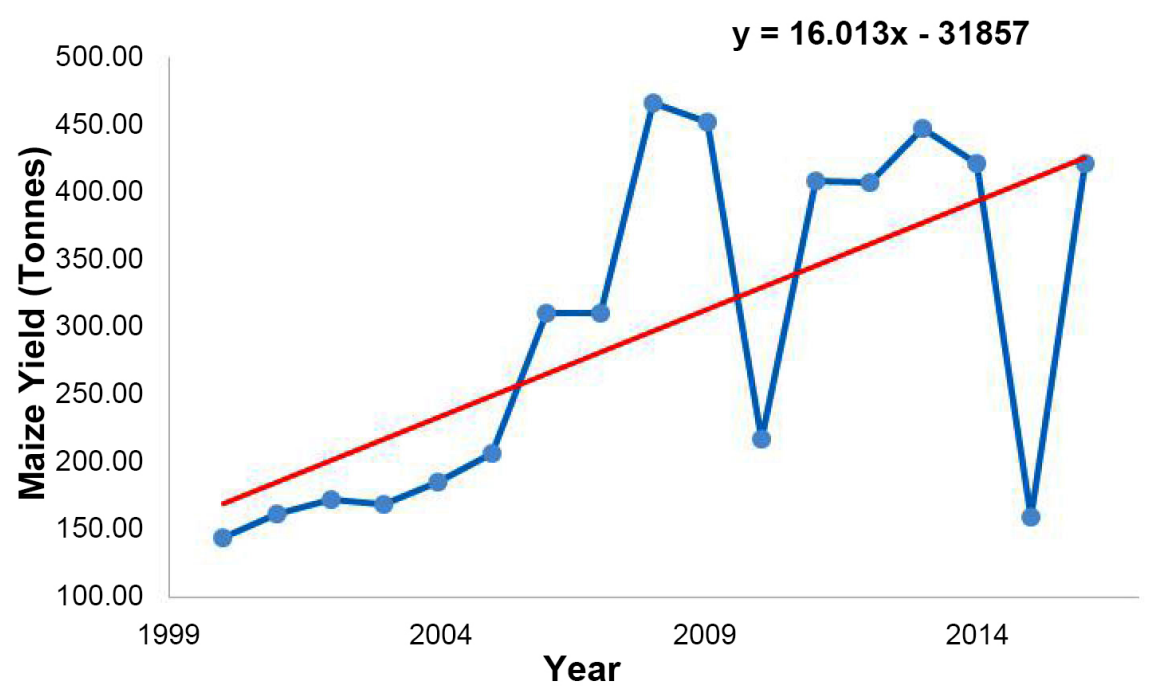

Figure 5. Yearly maize yield trend in Akure (2000-2016).

period of study. Highest yield figures were observed in 2008 with yield value of 465.7 tonnes and the least in 2000, yield value of 144.2 tonnes. Results of the test for significance at all levels of significance for the increase so observed showed a significant upward trend in yield values at $10 \%$ level of significance in the study area. This increase may not be unconnected to the favorable rainfall values earlier observed from the analysis performed while holding other factors of yield constant. [14] observed that crop yield is more sensitive to precipitation than temperature. Standard deviation of 196.1 and Coefficient of variation of $69.3 \%$. The mean yield value was 297.6 tonnes. Years 2000-2005, 2010 and 2015 had low Maize yield which were below mean maize yield value, while year 2006-2016 had higher maize yield value except year 2010 and 2015 that had values below the mean yield value. Most years with higher maize yield values had moderately high rainfall values, though year 2000, 2002 and 2004 all had low maize yield values 
despite the high rainfall values observed within the period, which suggest that other factors of yield like soil properties, rainfall requirements at different stages of the crop may also be considered for further study.

\subsection{Onset Dates of Maize Yield in Akure}

Figure 6 depicts a yearly variation in onset dates as rainfall onset dates was early in some years while other years were late, as noted by [2] who observed that in some years the rains start early, while in other years it arrives late. This yearly variation makes the planning of selection and sowing of crop types and varieties difficult. The mean onset date was $8^{\text {th }}$ of March, coefficient of variation of $13 \%$, the implication of this is that from one year to the other, onset of rainfall for the growing season is likely to change from the expected by about $13 \%$. Standard Deviation of \pm 9 days, in other words from one year to the next, onset of rainfall for the growing season is likely to commence 9 days before the expected date, just as much as it is likely to arrive 9 days later than the normally expected onset date. The earliest onset date was $22^{\text {nd }}$ Jan 2004 and $3^{\text {rd }}$ of April 2000 was the last onset date within the period of study which indicated some yearly variations as observed by [15] that rainfall onset dates could vary remarkably on annual basis. Most onset dates within the mean value and the expected date of departure from the mean had high maize yield values, except for year 2002 and 2003 and 2015 and 2016 which suggests that there is a probable chance that early onset dates will result into higher maize Yield as this will enhance longer length of growing season as indicated by [16] indicated that earlier onset dates most often led to longer rainy season. Year 2007, 2009, 2011 and 2014 also had high maize yield and did not fall within the mean dates, which suggest other factors may be responsible for the high maize yield.

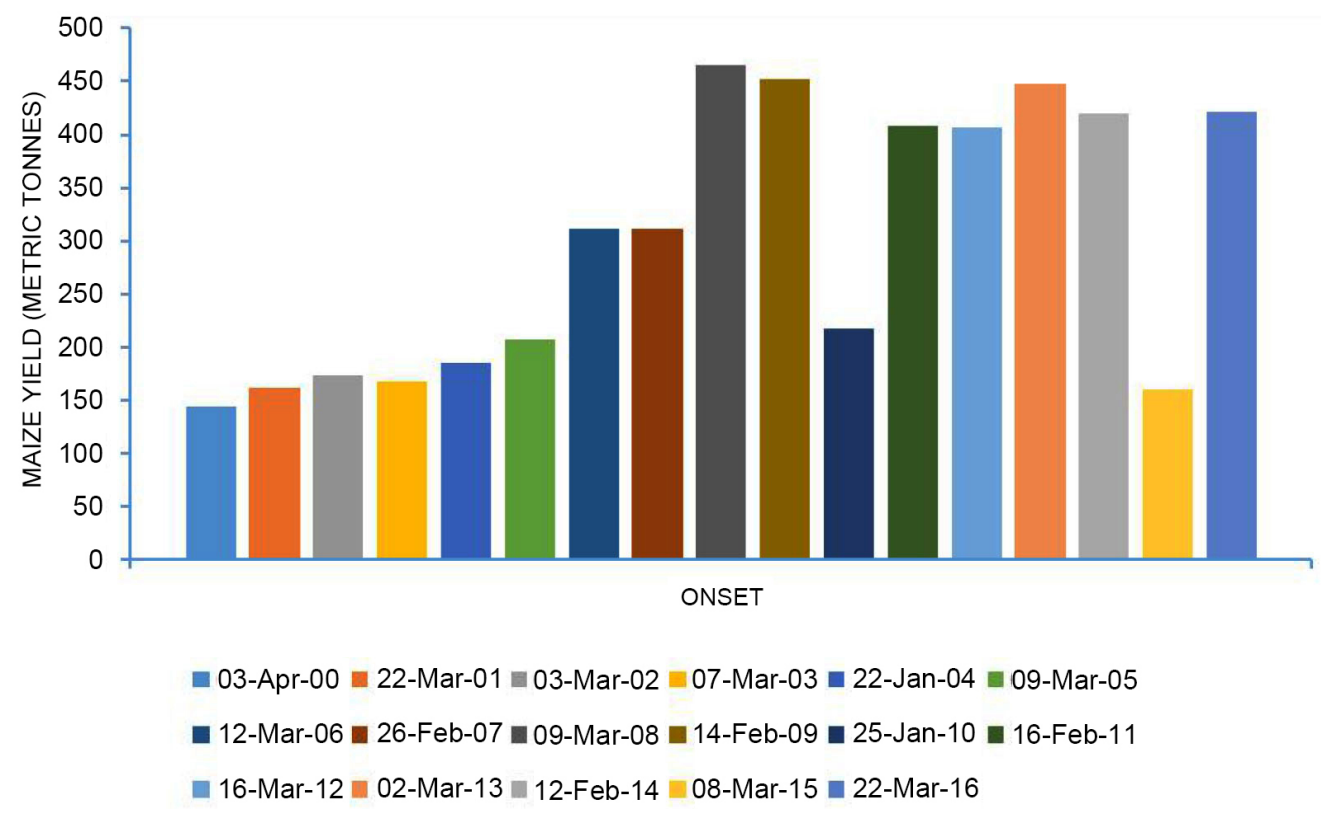

Figure 6. Yearly onset dates of maize yield in Akure (2000-2016). 


\subsection{Cessation Dates of Maize Yield in Akure}

Figure 7 revealed an earliest cessation date of $3^{\text {rd }}$ October 2013, and the last cessation date of $26^{\text {th }}$ November 2012 within the period of study. The mean cessation date for the period of study was $21^{\text {st }}$ of October \pm 21 days (see Table 1 ). It was observed from (Figure 7) that Cessation dates earlier than October $10^{\text {th }}$ in Akure had low maize yield. This was evident throughout the period under considerations, except for year 2011 and 2013 that had high yield values (Figure 7). This can possibly be that late cessation dates will result into higher maize yield as this will accommodate longer length of growing season. [17] observed from their study of rainfall characteristics and maize yield in Kwara State, Nigeria, that early onset date and late cessation date simply resulted to higher maize yield. Year 2002-2003 also showed low maize yield value despite their late cessation dates, which implies other factors beyond the scope of this work might be responsible for this.

Table 1. Rainfall onset dates, cessation and length of growing season.

\begin{tabular}{|c|c|c|c|}
\hline Year & Onset & Cessation & $\begin{array}{l}\text { Length of the Growing } \\
\text { Season (days per year) }\end{array}$ \\
\hline 2000 & 03-April & 06-October & 186 \\
\hline 2001 & 22-March & 21-October & 213 \\
\hline 2002 & 03-March & 11-November & 253 \\
\hline 2003 & 07-March & 11-November & 249 \\
\hline 2004 & 22-January & 06-October & 258 \\
\hline 2005 & 09-March & 10-October & 215 \\
\hline 2006 & 12-March & 11-October & 213 \\
\hline 2007 & 26-February & 01-November & 249 \\
\hline 2008 & 09-March & 11-November & 247 \\
\hline 2009 & 14-February & 11-November & 271 \\
\hline 2010 & 25-January & 11-November & 291 \\
\hline 2011 & 16-February & 03-October & 230 \\
\hline 2012 & 16-March & 26-November & 255 \\
\hline 2013 & 02-March & 03-October & 215 \\
\hline 2014 & 12-February & 11-November & 273 \\
\hline 2015 & 08-March & 04-October & 210 \\
\hline 2016 & 22-March & 05-November & 228 \\
\hline Mean & 8-March & 21-October & 238.6 \\
\hline Standard Deviation & \pm 9.0 & \pm 21.2 & \pm 26.9 \\
\hline Coefficient of Variation \% (CV) & 12.5 & 7.1 & 11.2 \\
\hline
\end{tabular}




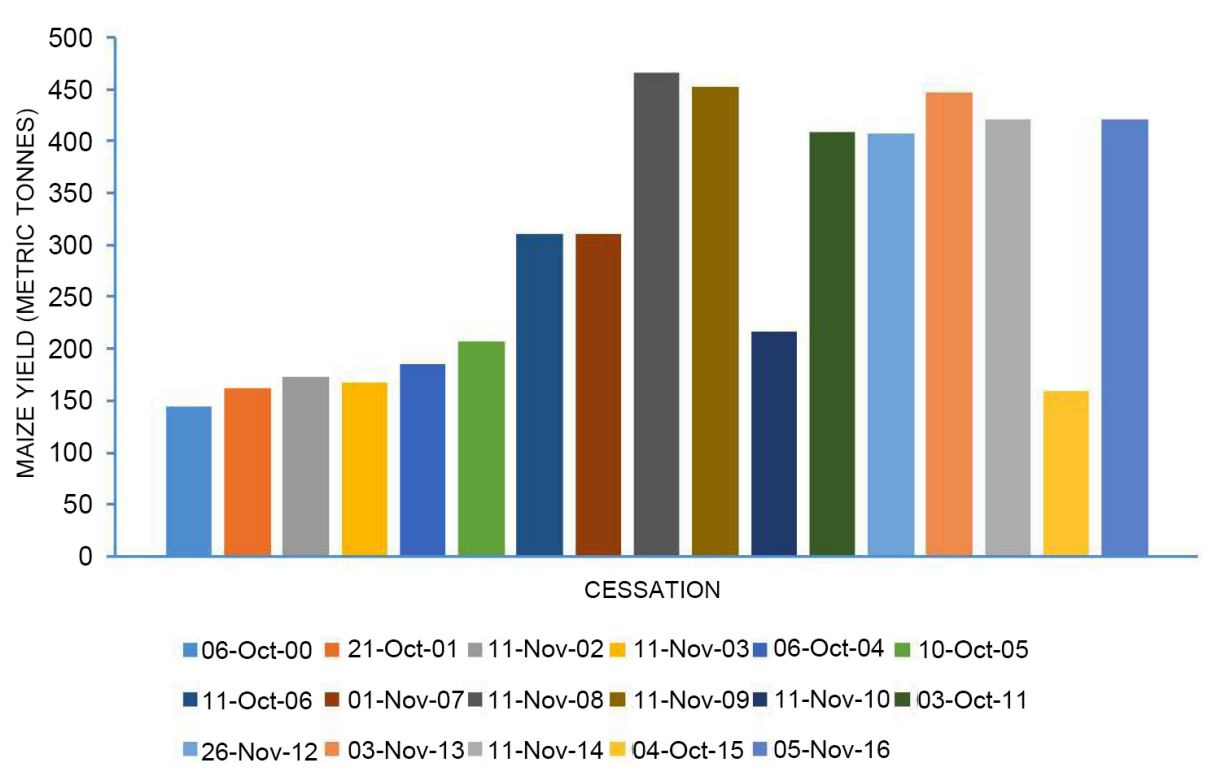

Figure 7. Yearly cessation dates of maize yield in Akure (2000-2016).

\subsection{Length of Growing Season of Maize Yield in Akure}

Figure 8 depicted the length of the growing season ranges from 186 days to 291 days within the study area as against [18] who observed that the length of the growing season ranged from 219 - 228 days over south west Nigeria. The coefficient of inter-annual variability of $11 \%$ (Table 2 ) was obtained from an average length of growing season of about 238 days with a standard deviation of \pm 27 days with the implication that length of the growing season, from one year to the other, on the average, is likely to increase or decrease by 27 days. Figure 8 further showed generally, a positive moderate correlation between maize yield and length of growing season in Akure for years 2001, 2002, 2003, 2004, 2006, 2007, 2008, 2009, and 2016, while negative correlation are evident in years 2005, 2010, 2011, 2012, 2013, and 2014. Most years with longer length of growing season like year, 2007, 2008, 2009, 2012, 2014 and 2016 had high maize yield value except years 2000-2005, and 2010, which possibly implies that longer length of growing season might contribute positively to maize yield values.

\subsection{The Single Linear Regression (SLR) Model between the Climatic Parameters and Maize Yield}

In this section the results of the regression analysis involving maize yield as the dependent variable on the one hand, and each of the climatic parameters as the independent variables on the other hand, taking each of these one at a time, are presented in this section. Based on the approach of the single linear regression model between maize yield and:

1) Rainfall;

2) Onset;

3) Cessation;

4) Length of the growing season (LGS); 


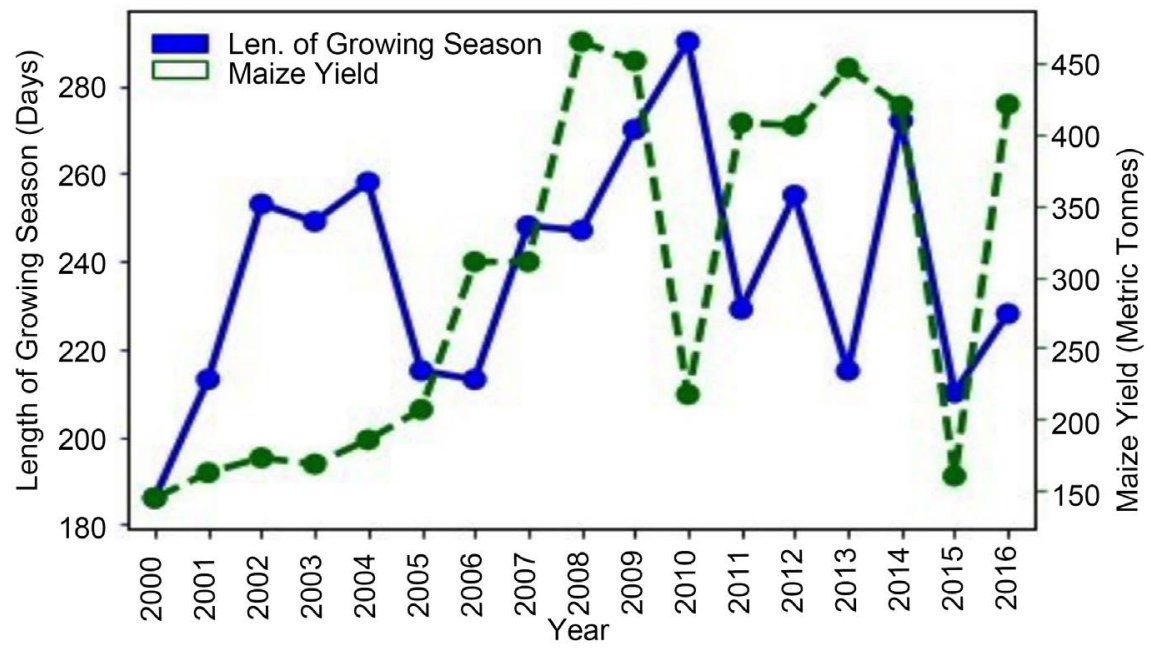

Figure 8. Yearly length of growing season of maize yield in Akure (2000-2016).

Table 2. Result of test of significance of the climatic parameters in the SLR model (significance of the parameters in relation to maize yield).

\begin{tabular}{ccc}
\hline Parameters & P-Value & Remarks \\
\hline Rainfall & 0.0095 & SS at $1 \%, 5 \%$ and $10 \%$ levels \\
Onset & 0.2434 & NSS at $1 \%, 5 \%$ and $10 \%$ levels \\
LGS & 0.1424 & NSS at $1 \%, 5 \%$ and $10 \%$ levels \\
Minimum temperature & 0.8409 & NSS at $1 \%, 5 \%$ and $10 \%$ levels \\
Maximum temperature & 0.5138 & NSS at $1 \%, 5 \%$ and $10 \%$ levels \\
\hline
\end{tabular}

NSS: Not statistically significant; SS: Statistically significant.

5) Temperature, are:

$$
y_{i}=-412.52+0.57 x_{i}
$$

$y_{i}$ is maize yield and $x_{i}$ is rainfall, $i=1,2, \cdots, 17$.

$$
y_{i}=532.77-2.44 x_{i}
$$

$y_{i}$ is maize yield and $x_{i}$ is onset, $i=1,2, \cdots, 17$.

$$
y_{i}=-235.42+2.06 x_{i}
$$

$y_{i}$ is maize yield and $x_{i}$ is cessation, $i=1,2, \cdots, 17$.

$$
y_{i}=-125.69+2.13 x_{i}
$$

$y_{i}$ is maize yield and $x_{i}$ is lgs, $i=1,2, \cdots, 17$.

$$
y_{i}=947.59-26.24 x_{i}
$$

$y_{i}$ is maize yield and $x_{i}$ is minimum temperature, $t_{\min }$.

$$
y_{i}=3004.44-83.37 x_{i}
$$

$y_{i}$ is maize yield and $x_{i}$ is maximum temperature, $t_{\max }$.

The coefficients associated to each of the climatic variables have been thus derived. Having derived the linear models, there is a need to test their individual 
significance as well as ascertain their performance in fitting the data. The former require computing the $t$-values of the individual parameters and subsequently the p-values, while the later would require computing the coefficient of determination and the Pearson coefficient of correlation.

\subsection{Significance of the Parameters in the Single Linear Regression (SLR) Model and Their Respective Coefficients of Correlation $(r)$ and Coefficients of Determination $\left(R^{2}\right)$}

The significance of each of the parameters in each of the linear model (Equation (13) to Equation (18)) will now be tested to ascertain the significance of each of the climatic parameters in contributing to maize yield. The computing the $t$-value of each of the parameters in the equations with which the corresponding $\mathrm{p}$-value is computed. The computed p-value is now compared with each of the levels of significance and the necessary conclusion is made as regards whether the parameter in the model contributes significantly or otherwise to maize yield. Additionally, the Pearson coefficient of correlation and coefficients of determination associated to each of the SLR model would be presented.

\section{Relationship between Maize Yield and Rainfall in Akure}

Figure 9 showed a strong positive correlation between maize yield and rainfall, which implies that as rainfall increases maize yield will possibly increase and vice-versa. For model Equation (16), involving maize yield and rainfall, the calculated $t$ and $p$ values (Table 1 and Figure 9) are 2.943 and 0.009539 respectively, indicating that at all the chosen levels of significance, rainfall is a major climatic variable contributing to maize yield. Furthermore, this result seems to be reinforced or reflected by the Pearson coefficient of correlation and determination given by $61 \%$ and $37 \%$ respectively. Here the value of $r=61 \%$ indicates that there is a strong linear relationship between maize yield and rainfall. [17] in

\section{$p$ value is: $0.0095 \quad y=0.5694 x-412.52$}

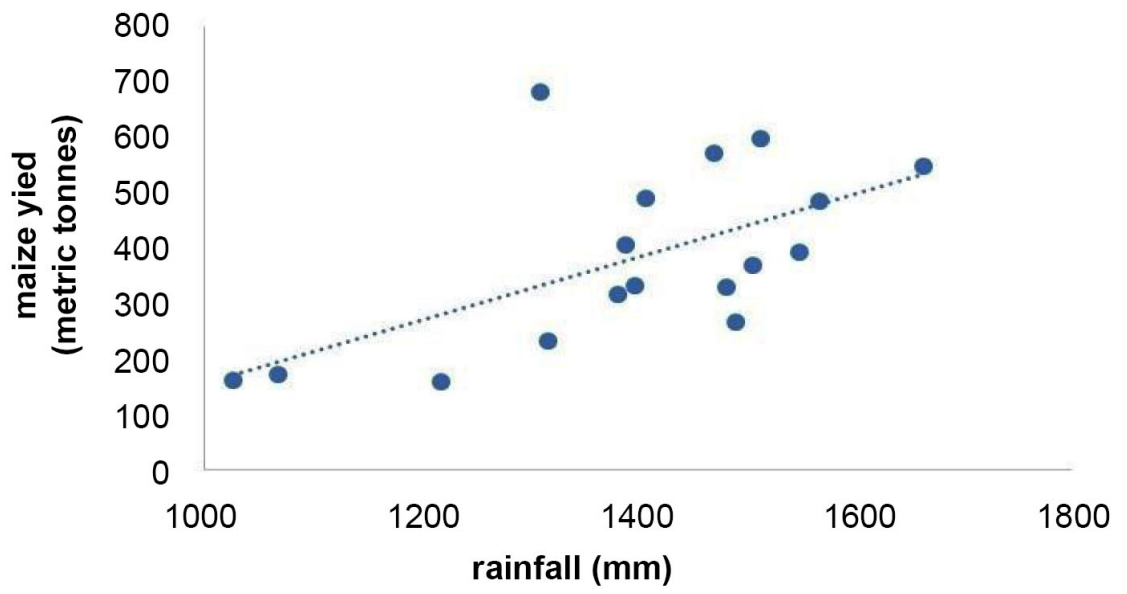

Figure 9. Yearly maize yield against rainfall (2000-2016). 
their study observed that though rainfall does not constitute the totality of the agricultural environment; it is an important factor in the rain-fed agriculture system of south west, Nigeria. The coefficient of determination indicates that about $37 \%$ of the total variation in maize yield can be explained by the variation in rainfall based on Equation (16).

\subsection{Relationship between Maize Yield and Onset in Akure}

Figure 10 depicts a negative correlation between the maize yield and onset of rainfall over Akure. It further revealed that the earlier the onset dates, the greater the prospect of having a higher maize yield, as postulated by [6] that early onset of rains contribute to better yield because grains have access to required mois ture pertinent for germination. For the regression model, Equation (17), maize yield and onset of rain, the calculated $t$ and $p$ values (Table 3 and Figure 10) are 1.211 and 0.2434 respectively, this indicates that, at all the levels of significance, the onset of rainfall does not contribute significantly to maize yield in Akure since the $\mathrm{p}$-value here is greater than all the levels significance, that is $\mathrm{p}$-value $=0.2434>$ $0.01,0.05$ and 0.1. Expectedly, the coefficient of correlation and determination

$p$ value is: 0.2434

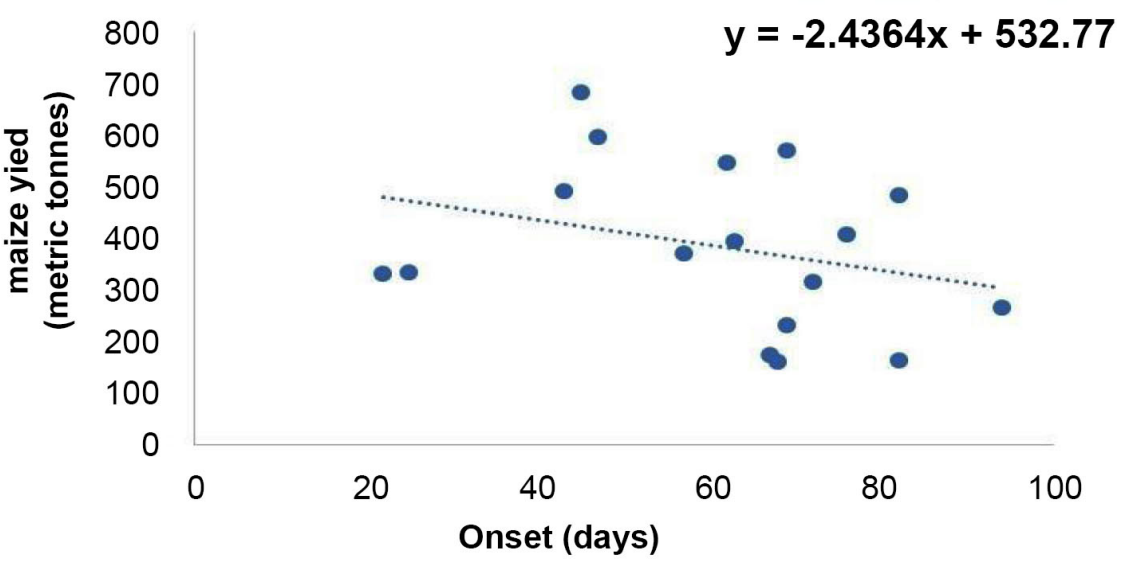

Figure 10. Relationship between maize yield and onset in Akure (2000-2016).

Table 3. Result of test of significance of the climatic parameters in the SLR model (significance of the parameters in relation to maize yield).

\begin{tabular}{ccc}
\hline Parameters & P-Value & Remarks \\
\hline Rainfall & 0.0095 & SS at $1 \%, 5 \%$ and $10 \%$ levels \\
Onset & 0.2434 & NSS at $1 \%, 5 \%$ and $10 \%$ levels \\
LGS & 0.1424 & NSS at $1 \%, 5 \%$ and $10 \%$ levels \\
Minimum temperature & 0.8409 & NSS at $1 \%, 5 \%$ and $10 \%$ levels \\
Maximum temperature & 0.5138 & NSS at $1 \%, 5 \%$ and $10 \%$ levels \\
\hline
\end{tabular}

NSS: Not statistically significant; SS: Statistically significant. 
are $30 \%$ and $9 \%$ respectively. Here the value of $r=30 \%$ which indicates a weak linear relationship between maize yield and onset; coefficient of determination indicates that about $9 \%$ of the total variation in maize yield can be explained by the variation in onset dates based on Equation (17).

\subsection{Relationship between Maize Yield and Cessation in Akure}

Figure 11 revealed a positive correlation between maize yield and cessation. It further showed that late cessation values will possibly enhance more maize yield. [19] corroborated that, maize requires considerable amount of moisture of about 500 to $900 \mathrm{~mm}$ of well distributed rain for optimal yield. Therefore, as cessation date of rains delay over the years it facilitates better moisture availability promoting growth and optimal maturation which invariably means better maize yield in the study area. Regarding the model, Equation (18), involving maize yield and cessation dates, the calculated $t$ and $p$ values (Table 3 and Figure 11) are 1.543 and 0.142 respectively, the implication of which is that, at all the levels of significance, rainfall cessation dates does not contribute significantly to maize yield in Akure since the p-value here is greater than all the levels of significance, that is, $\mathrm{p}$-value $=0.3552>0.01,0.05$ and 0.1 . Here, the coefficient of correlation and determination are $24 \%$ and $6 \%$ respectively. Where the value of $r=24 \%$ indicates a weak linear relationship between maize yield and rainfall cessation; coefficient of determination indicates that about $6 \%$ of the variation in maize yield can be explained by the variation in the cessation dates.

\subsection{Relationship between Maize Yield and Length of Growing Season in Akure}

Figure 12 showed an increasing trend between maize yield and length of growing season. This further suggest that the longer the length of the growing season the most probable the higher the maize yield. For the regression model Equation (19), involving the calculated $t$ and $p$ values (Table 2 and Figure 12) are 1.543 and 0.142 respectively, the implication of which is that, at all the levels of significance, the length of growing season does not contribute significantly to maize yield in Akure since the $\mathrm{p}$-value here is greater than all the levels significance, that is $\mathrm{p}$-value $=0.142>0.01,0.05$ and 0.1 . Here, the coefficient of correlation and determination are $37 \%$ and $14 \%$ respectively. The value of $r=37 \%$, indicates a weak linear relationship between maize yield and the LGS; coefficient of determination indicates that about $14 \%$ of the variation in maize yield can be explained by the variation in the cessation dates based on Equation (19).

\subsection{Relationship between Maize Yield and Minimum Temperature in Akure}

Figure 13 showed a weak negative correlation between maize yield and minimum temperature. For the regression model, Equation (20), involving the calculated $t$ and $p$ values (Table 3 and Figure 13) are 0.2039 and 0.5139 respectively, the implication of which is that, at all the levels of significance, the temperature 


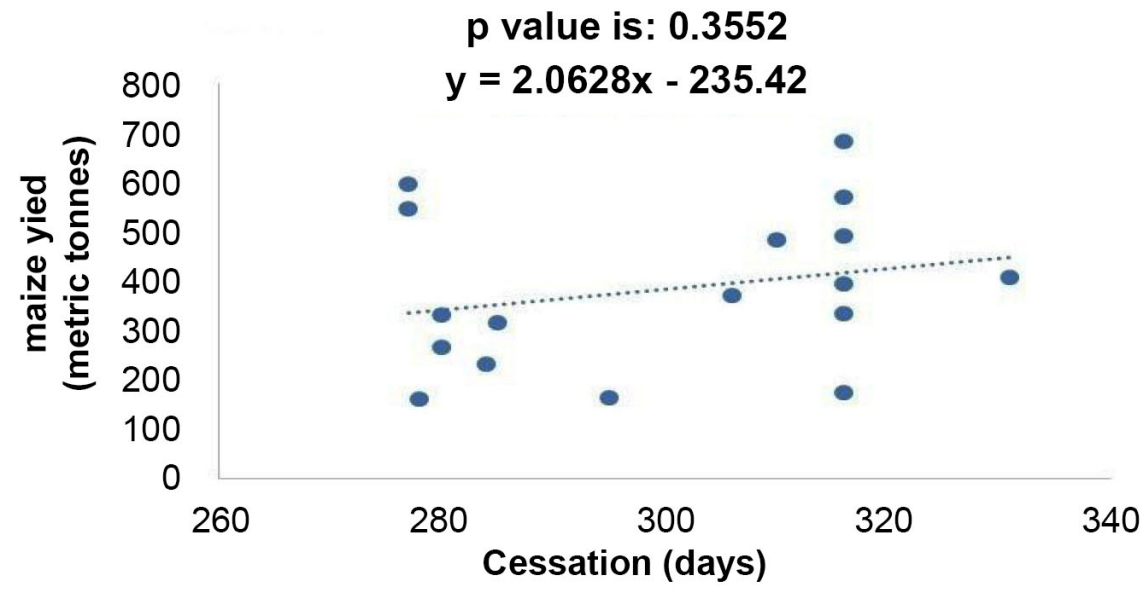

Figure 11. Relationship between maize yield and cessation in Akure (2000-2016).

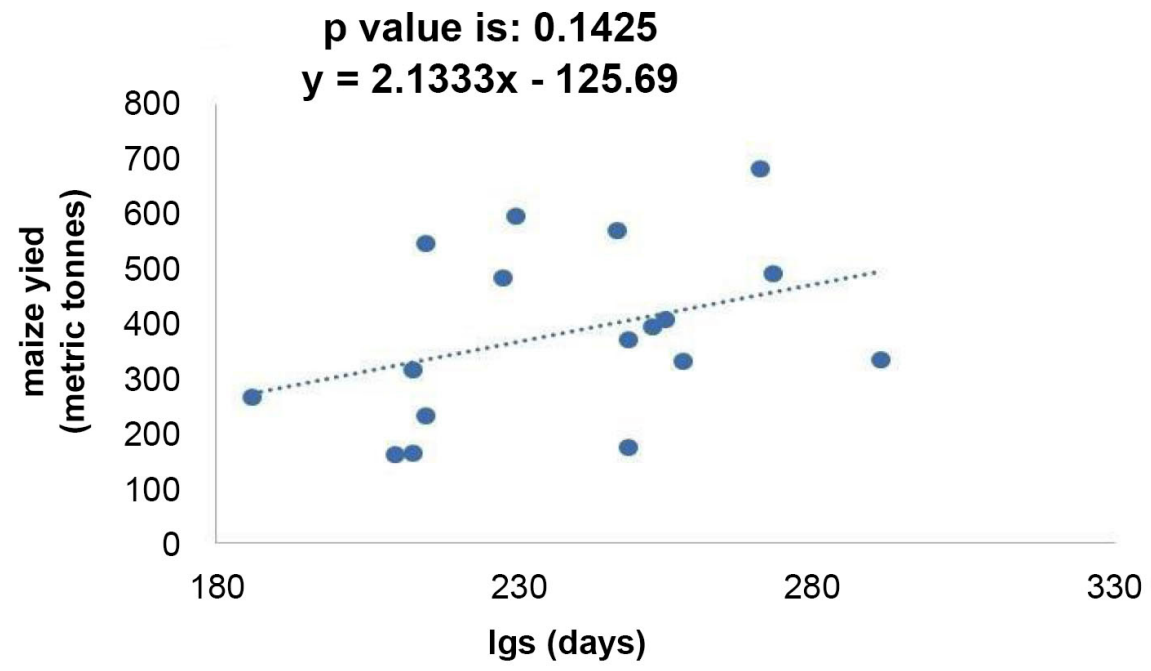

Figure 12. Relationship between maize yield and length of growing season in Akure.

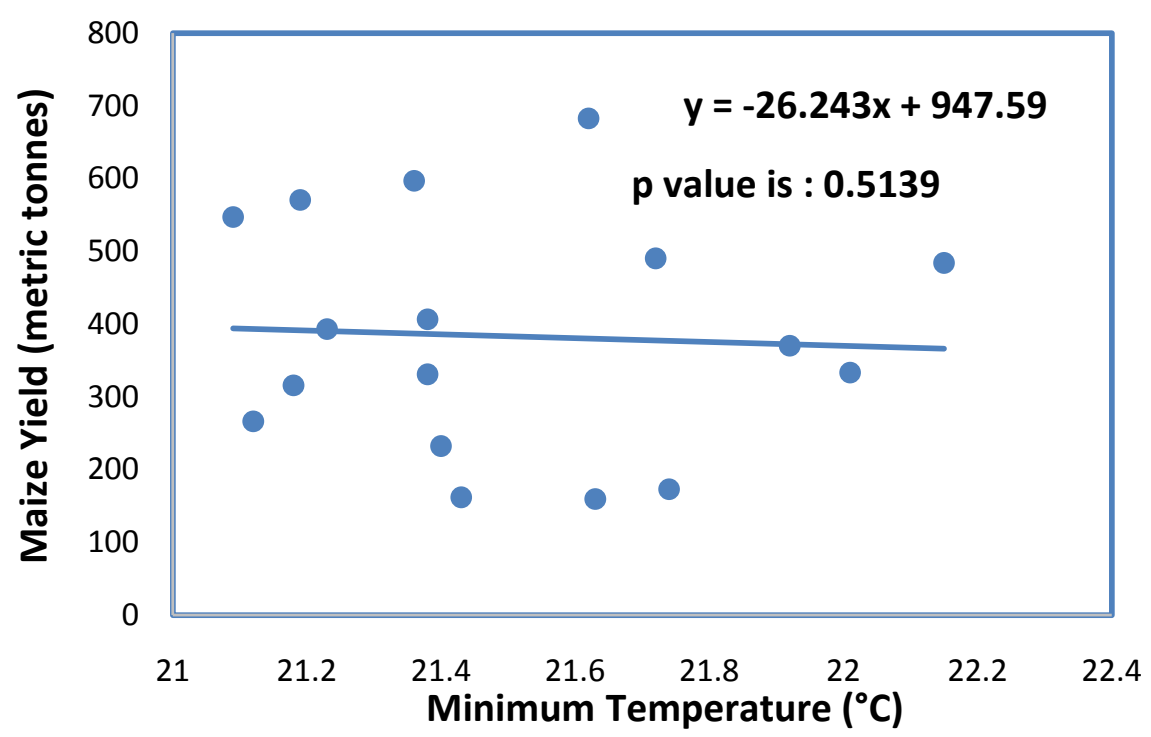

Figure 13. Maize yield against minimum temperature (2000-2016). 
or changes in minimum temperature do not contribute significantly to maize yield in Akure since the p-value here is greater than all the levels significance, that is $\mathrm{p}$-value $=0.5139>0.01,0.05$ and 0.1 . In this case the coefficient of correlation and determination are $5 \%$ and $0.3 \%$ respectively. Here the value of $r=5 \%$ indicates a very weak linear relationship between maize yield and minimum temperature; coefficient of determination indicates that a negligible portion of variation of $0.3 \%$ in maize yield can be explained by the variation in the cessation dates based on Equation (20). [20] also observed that in the tropics, temperatures are relatively uniform and seasonal variations are small, thereby allowing a wide range of suitable crops in relation to temperature conditions.

\subsection{Relationship between Maize Yield and Maximum Temperature in Akure}

Figure 14 revealed a negative correlation, which suggests that as maize yield increases maximum temperature decreases. And lastly in the case of the SLR model, Equation (21), involving maize yield and maximum temperature, the calculated $t$ and $p$ values (Table 3 and Figure 14) are 0.6676 and 0.8409 respectively, the implication of which is that, at all the levels of significance, the maximum temperature or changes in maximum temperature do not contribute significantly to maize yield in Akure since the p-value here is greater than all the levels significance i.e. $\mathrm{p}$-value $=0.8409>0.01,0.05$ and 0.1 , In this case, the coefficient of correlation and determination are $17 \%$ and $3 \%$ respectively. Here the value of $r$ $=17 \%$ indicates a weak linear relationship between maize yield and maximum temperature; as negate [21] noted that the rate of plant growth and development is dependent upon the temperature surrounding the plant. Coefficient of determination indicates that $3 \%$ of the variation in maize yield can be explained by the variation in maximum temperature based on Equation (17).

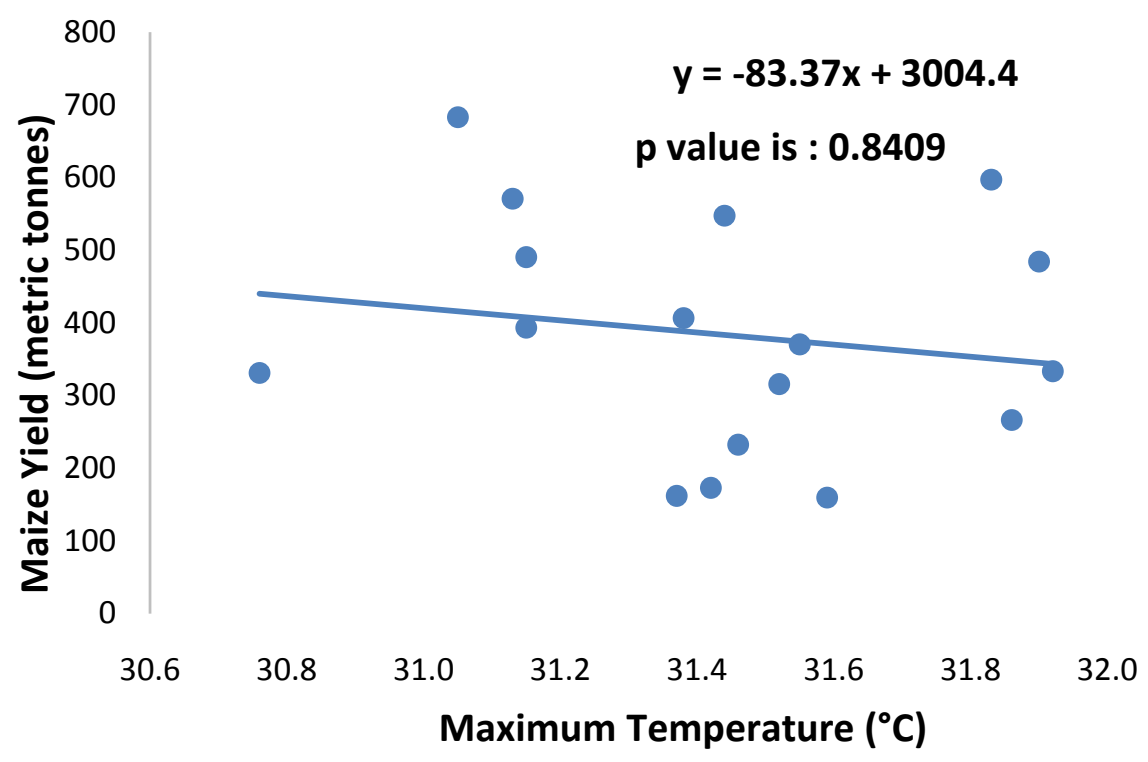

Figure 14. Maize yield against maximum temperature (2000-2016). 
Table 4. Result of test of significance of the climatic parameters in the MLR model (significance of the parameters in relation to maize yield).

\begin{tabular}{ccc}
\hline Parameters & p-Value & Remarks \\
\hline Rainfall & 0.0194124 & SS at $5 \%$ and $10 \%$ levels \\
Onset & 0.6310543 & NSS at $1 \%, 5 \%$ and $10 \%$ levels \\
LGS & 0.2077532 & NSS at $1 \%, 5 \%$ and $10 \%$ levels \\
Minimum temperature & 0.8607678 & NSS at $1 \%, 5 \%$ and $10 \%$ levels \\
Maximum temperature & 0.6732681 & NSS at $1 \%, 5 \%$ and $10 \%$ levels \\
\hline
\end{tabular}

NSS: Not statistically significant; SS: Statistically significant.

\subsection{Multiple Linear Regression Model (MLR) Involving Maize Yield and the Climatic Parameters in Akure}

In order to establish a relationship between maize yield and climatic parameters, a multiple linear regression relationship (MLR) between maize yield on the one hand and the independent or climatic parameters on the other hand, was also developed following the least-square approach outlined in Equation (3) and Equation (4). Therefore, a MLR equation establishing the relationship between yield and the climatic parameters is as presented thus:

$$
y_{i}=1062.25-66.97 x_{i 1}-25.61 x_{i 2}+1.29 x_{i 3}+2.95 x_{i 4}+0.56 x_{i 5}
$$

where, $x_{i 1}, x_{i 2}, x_{i 3}$ and $x_{i 4}, x_{i 5}$ are the minimum temperature, maximum temperature, onset, length of growing season and annual rainfall with: $\beta_{1}, \beta_{2}, \beta_{3}, \beta_{4}$ and $\beta_{5}$ as their respective coefficients. The coefficient of determination and the Pearson correlation coefficient associated with the MLR model are 0.51 (51\%) and $0.72(72 \%)$ respectively. This computed coefficient of determination indicates that over $51 \%$ of the variability in maize yield can be explained by the variation in climatic parameters during the period of study, while the Pearson coefficient of correlation indicates that there is a strong linear relationship between maize yield and the climatic parameters in the excess of $70 \%$. However, when each of the climatic parameters was subjected to a statistical test to ascertain the significance of their individual contribution to maize yield using $t$ and $p$ value approach, the result of the test indicated that annual rainfall amount is the only parameter whose contribution is significant to maize yield at $5 \%$ and $10 \%$ level. Even though other parameters may have contributed to maize yield, their contributions were however not statistically significant at the $1 \%, 5 \%$ and $10 \%$ levels (see Table 4).

\section{Conclusion}

The evaluation of onset, cessation of rainfall, and temperature on maize yield in Akure, Ondo State show that rainfall is a major climatic variable contributing to maize yield in the study area. The study further reveals that maize yield does not depend solely on rainfall onset, cessation dates and length of growing season, especially as their contributions were not statistically significant. The maximum 
and minimum temperatures, though both in an increasing trend, do not have significant effect on the maize yield over the period of consideration.

\section{Conflicts of Interest}

The authors declare no conflicts of interest regarding the publication of this paper.

\section{References}

[1] Olaniran, O.J. (1983) The Onset of the Rains and the Start of the Growing Season in Nigeria. Nigerian Geographical Journal, 26, 81-88.

[2] Odekunle, T.O. (2004) Rainfall and the Length of the Growing Season in Nigeria. International Journal of Climatology, 24, 467-479. https://doi.org/10.1002/joc.1012

[3] Odekunle, T.O., Balogun, E.E. and Ogunkoya, O.O. (2005) On the Prediction of Rainfall Onset and Retreat Dates in Nigeria. Theoretical and Applied Climatology, 81, 101-112. https://doi.org/10.1007/s00704-004-0108-x

[4] Salack, S., Muller, B. and Gaye, A.T. (2011) Rain-Based Factors of High Agricultural Impacts over Senegal. Part I. Integration of Local to Sub Regional Trends. Theoretical and Applied Climatology, 106, 1-22. https://doi.org/10.1007/s00704-011-0414-z

[5] Mugalavai, E.M., Kipkorir, E.C., Raes, D. and Rao, M.S. (2008) Analysis of Rainfall Onset, Cessation and Length of Growing Season for Western Kenya. Agricultural and Forest Meteorology, 148, 1123-1135. https://doi.org/10.1016/j.agrformet.2008.02.013

[6] Ndomba, P.M. (2010) Development of Rainfall Curves for Crops Planting Dates: A Case Study of Pangani River Basin in Tanzania. Nile Basin Water Science and Engineering Journal, 3, 13-27.

[7] Guenang, G.M. and Kamga, F.M. (2012) Onset Retreat and Length of the Rainy Season over Cameroon. Atmospheric Science Letters, 13, 120-127. https://doi.org/10.1002/asl.371

[8] Odekunle, T. (2006) Determining Wet Season Onset and Retreat over Nigeria from Precipitation amount and Number of Wet Days. Applied Climatology, 83, 193-201. https://doi.org/10.1007/s00704-005-0166-8

[9] Ati, O.F., Stigter, C.S. and Oladipo, E.O. (2002) A Comparison of Methods to Determine the Onset of the Growing Season in Northern Nigeria. International Journal of Climatology, 22, 731-742. https://doi.org/10.1002/joc.712

[10] Ojo, O., Ojo, K. and Oni, F. (2001) Fundamentals of Physical and Dynamic Climatology. SESEC Publishers, Lagos, Nigeria.

[11] Lobell, D.B., Schlenker, W. and Costa-Roberts, J. (2007) Climate Trends and Global Crop Yield Since 1980. Science, 333, 616-620. https://doi.org/10.1126/science.1204531

[12] Niang, I., et al. (2014) Africa. In: Barros, V.R., et al., Eds., Impacts, Adaptation, and Vulnerability. Part B: Regional Aspects. Contribution of Working Group II to the Fifth Assessment Report of the Intergovernmental Panel on Climate Change, Cambridge University Press, Cambridge, UK, 1199-1265. https://doi.org/10.2134/agronj2010.0303

[13] Hatfield, J.L., Boote, K.J., Kimbal, L.H., Ziska, R.C., Izaurrald, D.O., Thomson, D.W. and Agron, J. (2011) Climate Impact on Agriculture: Implications for Crop Yield. Agronomy Journal, 103, 351-370. 
[14] Kang, Y., Khan S. and Ma, X. (2009) Climate Change Impacts on Crop Yield, Crop Water Productivity and Food Security-A Review. Progress in Natural Science, 19, 1665-1674. https://doi.org/10.1016/j.pnsc.2009.08.001

[15] Ezenekwe, L.N., Ezemonye, M.N. and Emeribe, C.N. (2013) Appraisal of the Characteristics of Rainfall in Kano. British Journal of Advance Academic Research, 2, 20-28.

[16] Amekudzi, L.K., Yamba, E., Preko, K., Asare, E.O, Aryee, J., Baidu, M. and Codjoe, N.A.S. (2015) Variabilities in Rainfall Onset, Cessation and Length of Rainy Season for the Various Agro-Ecological Zones of Ecological Impacts of Climate. Change, 3, 416-434. https://doi.org/10.3390/cli3020416

[17] Ifabiyi, I.P. and Omoyosoye, O. (2011) Rainfall Characteristics and Maize Yield in Kwara State, Nigeria. Online International Journal, 1, 60-65.

[18] Sobowale, A., Sajo, S.O. and Ayodele, O.E. (2016) Analysis of Onset and Cessation of Rainfall in Southwest Nigeria: Food Security Impact of Variability in the Length of Growing Season. Hungarian Agricultural Engineering, No. 30, 23-30. https://doi.org/10.17676/HAE.2016.30.23

[19] Ikpe, E. (2014) Adaptation Strategies to Climate Change, among Grain Farmers in Goronyo Local Government Area of Sokoto State Nigeria. M.Sc. Thesis, Department of Geography, Ahmadu Bello University, Zaria.

[20] Nieuwolt, S. (1982) Tropical Climatology: An Introduction to the Climates of the Low Latitudes. John Wiley \& Sons, Hoboken.

[21] Hatfield, J.L. and Prueger, J.H. (2015) Temperature Extremes: Effect on Plant Growth and Development. Weather and Climate Extremes, 10, 4-10.

https://doi.org/10.1016/j.wace.2015.08.001 